\title{
Evaluation of Search Engines: A Conceptual Model and Research Issues
}

\author{
Ramaraj Palanisamy ${ }^{1}$ \\ ${ }^{1}$ Department of Information Systems, St Francis Xavier University, Canada \\ Correspondence: Ramaraj Palanisamy, Department of Information Systems, The Gerald Schwartz School of \\ Business, St Francis Xavier University, Antigonish, Canada. Tel: 1-902-867-2184. E-mail: rpalanis@stfx.ca
}

Received: September 19, 2012 Accepted: December 12, 2012 Online Published: February 20, 2013

doi:10.5539/ijbm.v8n6p1 URL: http://dx.doi.org/10.5539/ijbm.v8n6p1

\begin{abstract}
This paper examines the evaluation of search engines by developing a conceptual model based on the literature. The model identifies the key factors that influence user evaluation of search engines, effective and efficient criteria for evaluation by considering user satisfaction and usage as the search engine success variables. The model attempts to identify the attributes that determine a good search engine, why users repeatedly visit their favorite search engines, and why users switch between different search engines. The research issues are evolved out of the conceptual model; the implications for searchers and search engine providers are given.
\end{abstract}

Keywords: search engine performance, evaluation of search engine, criteria for evaluation, search engine success, conceptual model

\section{Introduction}

The most performed activities by Internet users are searching for specific information together with email services. Search engines are one of the major information retrieval tool that users use to find various kind of information from the Internet (Rangaswamy et al., 2009). For instance, in e-commerce, search engines often act as the gate keepers for gathering information about products, browse products, or make purchases only after the websites of interest have been identified using search engines (Kraut et al., 1996). Users interact with online informational retrieval systems using powerful tool such as search engines (Liaw \& Huang, 2006) to retrieve better information in an efficient way (Jansen et al., 2008). An international survey (OCLC, 2005) report that 89 percent of information searches undertaken by college students begin with a search engine and the same trend is observed for faculty and researchers. Internet search engines are the first option for people who want to find information about anything (Kim, 2009). Thereby search engines have become an integral part of information environment and they are replacing the role of libraries in facilitating information retrieval and access (Rieger, 2009). As a result, there has been a rapid growth in the Web Search engine market and search engines continue to attract a large number of online users / Web searchers and regularly rank as heavily visited sites in terms of the number of visitors (Alexa Internet Inc., 2008).

There are numerous search engines including the generalist (Bing, Google, Sapo and Yahoo!), health-specific (Medline Plus, Sapo Sau'de and Web MD) and other search engines available on the Internet (Lopes \& Ribeiro, 2011) that can help users find any information, anywhere on the web, or even beyond it. Web-based information retrieval systems would collapse if search engines were not available on the Internet (Liaw \& Huang, 2003). Among the various search engines, Google is the most visited website in the world (Alexa, 2010) and Googling has become synonymous with researching (Mostafa, 2005). Other search engine companies such as Yahoo!, Excite, Lycos, Altavista, HotBot, Bing, Ask, AOL, and other portal sites believe that they gain competitive advantage by acquiring long-term repeat users. Though the business model followed by these companies relies on the fact that users will be repeatedly choosing their favorite search engines, it is not clear as to what might lead to such repeat visits or how users interact with search engines for information retrieval.

With the tremendous amount of diversity content on the Internet, retrieving relevant information is so important for the users. So, in the recent years, attention has shifted away from information retrieval (IR) to evaluation of search engine performance (Leroy et al., 2007). The existing IR research evaluates the performance of search engine tools in terms of precision and recall (Baujard et al., 1998), compares the retrieval effectiveness of online search engines with single keyword and questions- answering tasks (Bin \& Lun, 2001). As the experience with a 
search engine will determine to use and reuse the search engine, it becomes important to study how Internet users interact with and evaluate their experience with search engines.Though the user's interactions with search engines are often brief, users will however form an opinion of the search tools that they have used. Besides, for the progression of web retrieval system development mainly depends on how the end-users perceive the search engine tools (Johnson \& Crudge, 2007) and evaluating information retrieval systems is central to information science (Su, 2003a). There is a lack of knowledge on how users evaluate search engines and tools when they use them for information searching and retrieval. To fill this gap, a conceptual model for evaluating search engines has been developed based on a review of literature. The model identifies the key factors that influence user evaluation of search engines and eventually identify the attributes that determine a good search engine, why users repeatedly visits their favorite search engines, and why users switch between different search engines.The rest of the paper is organized as follows. The section 2 describes the research methodology; the section 3 reviews the literature on the evaluation of search engines; section 4 evolves a conceptual model for evaluating search engines; based on the conceptual model section 5 discusses the various issues for research followed by the implications for practice and research with conclusions in section 6 .

\section{Research Methodology}

Developing an appropriate methodology for evaluating information retrieval system is central to information science and information retrieval systems ( $\mathrm{Su}, 2003 \mathrm{a})$. To facilitate this process, this research falls into answering the following questions: (1) What are the influences for users to use a search engine? (2) What are the intentions of a user in using a search engine? (3) What are the criteria used in evaluating a search engine? (4) How a search engine could be effectively used? (5) How a search engine could be efficiently used? (6) How the satisfaction of the users could be increased in using a search engine? Accordingly, this review concentrates on the following aspects: the influences (environmental and user-related) for using a search engine, criteria (effectiveness and efficiency) used in evaluating a search engine, intentions to use a search engine, user satisfaction and usage in using a search engine.

A literature survey was employed in the study to explore these aspects from perspective of evaluating information retrieval system such as search engine. The literature was collected primarily from publications in the area of information retrieval systems, web searching, user characteristics in web search, information seeking behavior, human interaction with web, search engine performance, user satisfaction, and system usage. The literature search includes journals published by numerous publishers in particular Emerald, ACM, IEEE and Elsevier, as they are well reputed. The aim of literature search was to explore the evaluation of search engines by developing a conceptual model thereby identify the research issues based on the model.

\section{Evaluation of Search Engines}

As the Internet provides unlimited amounts of information that can be accessed with low effort and cost, search engine represents powerful tool that assists the Internet users in their interaction with the online environment (Liaw \& Huang, 2006). A search engine is an information retrieval system with a set of programs with search tools used to perform searches (Liaw \& Huang, 2003), designed, developed, and used for finding information from the web (Katz, 2010) using different strategies. Search engines perform the basic retrieval task including the acceptance of a query, a comparison with a database and the production of retrieved digital information such as text, audio, video, data and simulations (Rieger, 2009; Rowley, 1998). A search engine tool is a utility available in the Internet in which the user inputs specific name, subject, and/or key words for the purpose of retrieving a list of web links that match the user's query terms (Vaughan, 1999). The search engine facilitates the users to apply their criteria to a database to build a set of matches. The examples include Google, Yahoo!, AltaVista, Webcrawler, Lycos, Excite, Infoseek, Excite, HotBot, Bing, Ask, AOL, and other portal sites. Usually the search engine indexes with automatic software and the catalog is built manually with human input.Search engines gather web pages that form the universe from which the users retrieve information by issuing queries and the required information is retrieved by using information retrieval algorithms (Gordon \& Pathak, 1999). Usually the search engines provide search services on the web based on directory services and query based (Liaw \& Huang, 2003). The directory services (e.g. yahoo) provide a hierarchical organization of resources developed by human cataloguers (Callery \& Tracy-Proulx, 1997); the query based services (e.g., Excite) provide broad coverage of the Internet through intensive automation of query retrieval process (Jenkins et al., 1998). Users usually search for information trying to maximize the accuracy of search outcome with minimum effort exerted to acquire it (Bettman, 1979).

It is important to focus on how end users interact with and evaluate their experience in using the search engines (Leroy et al., 2007). A framework for evaluating search engines is provided by Sutcliffe \& Ennis (1998) 
consisting of four steps: (i) problem identification (ii) need articulation (iii) query formulation and (iv) results evaluation. During problem identification, a user realizes the need to retrieve information; in the 'need articulation' stage the user consult external sources for the required information or formulate the terms (from the user's own domain knowledge) to search; during query formulation the user combines the terms in query suitable for a search engine; and finally during results evaluation stage the required information is compared with the retrieved information.

Though the user's interactions with search engines are often brief, users will form an opinion of the search engine and tools used (Spink et al., 2001) and these impressions form "mental models" resulting from the user's interactions with search engines (Johnson \& Crudge, 2007). These mental models facilitate the users in evaluating the search engines and represent the user's evaluative view which can be used to understand the user-based criteria for evaluation. Some of the user-based/ user-centered criteria are effectiveness, efficiency, interaction/ usability, and overall satisfaction and/or success (Su, 2003a; Spink, 2002; Johnson et al., 2001). Effectiveness refers to the impact of users' interactions with search engines and usability refers to the capabilities of the search engine. In general, the criteria are diminishing the effort and cost of search and improving the decision-making process in using the search results (Haubl \& Trifts, 2000). In particular, the following criteria are used for evaluating search engines:

- value of the search results - major features (options that make the site unique, informative, and any value addition to the search results) - quality of retrieved items (proving current and authoritative information) (Jones \& Timm, 2008)

- convenience of various search tools

- ability of search engines to locate information on the Internet

- the usability of search tools (interface design -availability of basic and advanced search features with instructions for effective searches - overall ease of use) (Su, 2003b; Vaughan, 1999) - most frequently applied measure

- $\quad$ effectiveness (number and precision or relevance of returned results) (Ziff-Davis, 1995)

- search engines' capacity to retrieve the information that matches user's informational needs (Pan et al., 2007)

- comprehensiveness of the Web engines by number of documents indexed (Venditto, 1996)

- $\quad$ search capability options, how the results were displayed (readability), update frequency of information (Courtois et al., 1995)

- browsability (ease of understanding results) -navigation (easy-to-use format for finding and viewing the information) (Jones \& Timm, 2008)

- customizability (ability to construct a search to weed out irrelevant results)

- name (the name of the site), on-screen help, speed (response time/ timeliness), database coverage, number of links, accessibility and others.

\section{A Conceptual Model for Evaluating Search Engines}

A conceptual model for evaluating search engines is shown in Figure 1. This model is based on user evaluation of web search engines model developed by Su (2003a, 2003b) and technology acceptance model (TAM) developed by Davis (1989) and Davis et al., (1989). Su (2003a) suggested that there are many factors that influence user evaluation of search engines including: system features, search interface, documentation, output display, relevance of results, interface-ease, expectancy, connectivity, and user-prior experience. TAM is widely used for understanding user behavior in technology usage and the model shows how users gain the willingness to accept and use a new system or technology. In the TAM, the user tries the computer system and forms perceptions about its usefulness (perceived usefulness) and ease of use. These perceptions on ease of use and usefulness then influence the user's intention to use the computer system. Since a search engine is a web-based information system, the proposed model includes satisfaction and usage as search engine (information systems) success variables.

Since the proposed model is part on the TAM, here is a logical scenario of the proposed model. A user tries a targeted search engine at least once, and then evaluates the search engine's performance in terms of effectiveness and efficiency. In this process the user forms an (emotional) opinion about the search engine, develop an attitude and estimate the learning cost. As a result, if the user is satisfied with the search engine, she or he intends to 
continue using the search engine. This intent will make the user to continued use. On contrary, if the user is not satisfied with the search engine, then the user will not use it again. Davis et al., (1989) compared two theoretical models (Technology Acceptance Model and Theory of Reasoned Action) developed to explain users' behavioral intent. In the comparison of both the models (TAM and TRA), attitude precedes the behavioral intent (in the proposed model, Intention to (re)use the search engine). User satisfaction is an attitude toward using the search engine and it precedes the behavioral intent to (re)use the search engine. Also, TAM suggested that the user will gain the intention of using a system prior to actual usage.

Furthermore, Jansen et al., (2009) conclude that major search engine brands have a measureable positive effect on search engine performance evaluation. Accordingly, the conceptual model groups the evaluation criteria, influences and search engine success into seven components: brand (external/ environmental influences), user-related influences (internal), effectiveness related criteria, efficiency related criteria, intent to use a search engine, user satisfaction and usage. The model has been formulated in view of the Theory of Reasoned Action (Ajzen, 1991) so that user-related influences, effectiveness and efficiency point towards user satisfaction. Then the two variables user satisfaction and environmental directly influence intent to (re)use a search engine. In this model user satisfaction constitutes an attitude toward the behavior (TRA) and environmental influences represent subjective norms (TRA). The individual components presented in the appropriate group are described in more detail in the following section.

\subsection{Environmental Influences (External)}

\subsubsection{Brand and Brand Equity}

Branding of a search engine is a significant factor in determining search engine use behavior (Rieger, 2009) and has a positive effect on search engine performance evaluation (Jansen et al., 2009). For example, Google as a well-known brand made a significant impact on using it as a (re)search engine (Pan et al., 2007). A brand is a unique identifying feature that distinguishes one product from another. A brand for an organization is defined as the intangible sum of an organization's attributes which can reflect the name of the organization, its history and reputation (Jansen et al., 2009). It can be recognized by tangible features such as symbol, sign, name, and design or by intangible features such as values, ideas, and personality or combinations of these (Stern, 2006; Kotler, 1967).

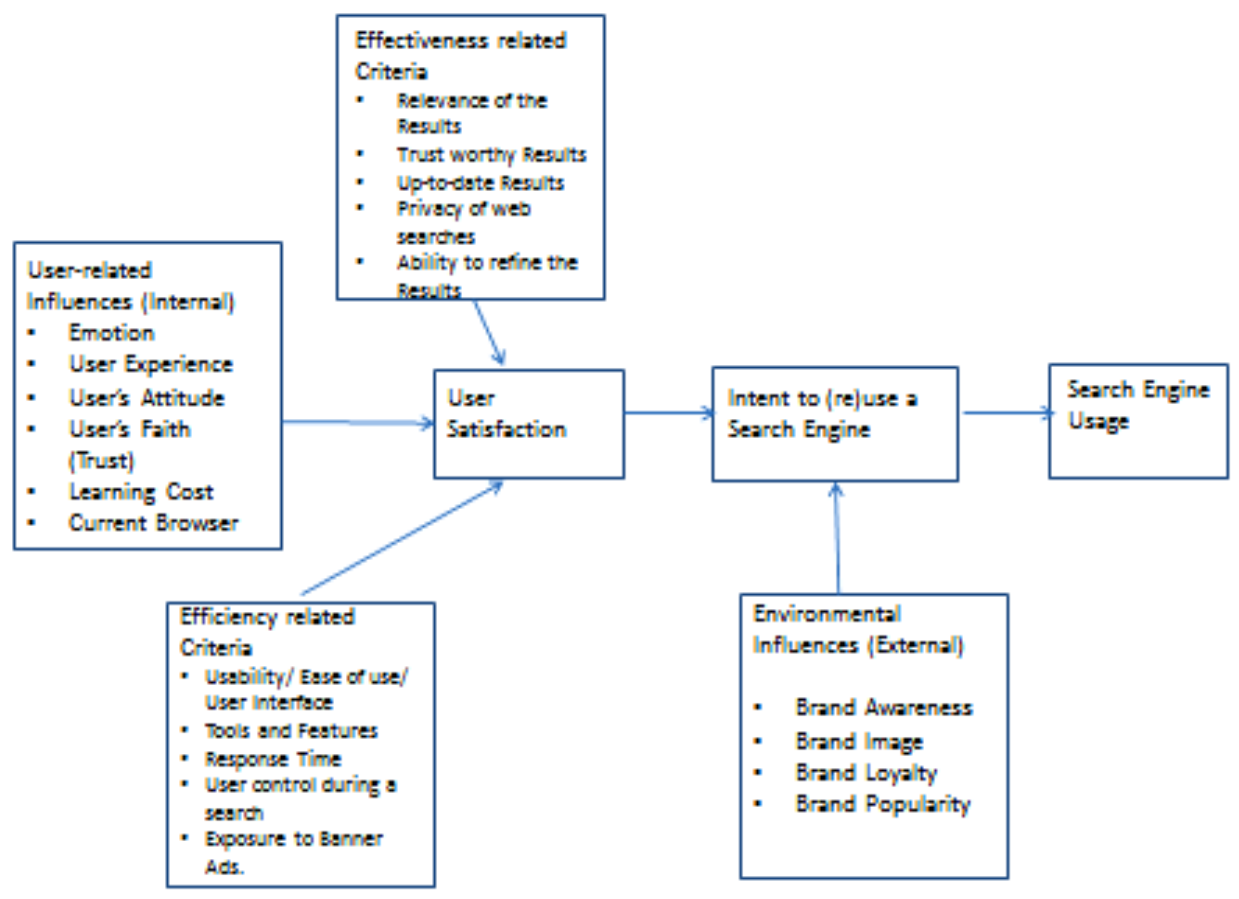

Figure 1. A concept model for evaluating a search engine

Most of the search engines have similar layout and functions so brand plays an important role to separate one search engine from another and developing consumer loyalty. Brand plays a role in the searching process and it 
affects overall Web search at different stages including search engine selection, search engine results page evaluation, individual link evaluation, and evaluation of the landing page (Jansen et al., 2009). In general, users attach a high degree of trust in major search engine brands and it affects user perception in regard to search engine performance and users generally see their favorite and popular search engine in a positive manner. Thus a brand may put forth an identification image, a discrimination factor, a quality assurance symbol, a prestige or trust function (Keller, 2007).

Brand equity stands for the value of the brand. There are three ways to measure brand equity, including customer mindset, product market outcomes and financial market outcomes (Ailawadi et al., 2003). The proposed conceptual model emphasizes brand equity from customer perspective. Accordingly, customer-based brand equity assesses brand from the following perspectives: brand awareness, brand loyalty, brand image and brand popularity (Jansen et al., 2009; Ye \& Van, 2004; Keller, 1993).

\subsubsection{Brand Awareness}

Brand awareness can be understood as a "brand recognition memory" (Ye \& Van, 2004). It can be measured as whether a consumer can recognize and recall a brand image/ name or not. Brand awareness is a main contributor to brand equity (Jansen et al, 2009) and plays an important role in consumer decision-making processes (Keller, 1993). First, it reminds consumers of some specific brands when they think about a product category. Second, it affects consumers' consideration and decision making results. Finally, it enhances consumers' association with the brands. To sum up, the consumer awareness of search engine brands will influence recognition and selection of the search engine.

\subsubsection{Brand Image}

Brand image is defined as "perceptions about a brand as reflected by the brand associations held in the consumer memory" (Keller, 1993). Brand associations are the information held in consumer's memory which contains the meaning of the brand. One common way to measure brand associations is through brand attitudes (George \& Charles, 2000). Brand attitudes are consumers'overall evaluations of a brand. Keller (1993) claimed that brand attitudes are important because they are the basis for consumer behavior. Accordingly users' favorable attitudes toward a search engine brand will lead to positive brand images held in memory.

\subsubsection{Brand Loyalty}

The consumers only have limited resources and hesitate to try all alternatives. Brand loyalty plays an important role in consumer decision-making process. Since there will be an impact of past choices on current choices, brand loyalty is "inertia" where the users do not even consider other brands (Jeuland, 1979) and hence lead to repeat use. Brand loyalty is measured by tracking consumers' repeat purchase or usage (Telang et al., 2001) and through switching behavior (Yi \& Jeon, 2003). Consumers will be less likely to switch to another brand when they are loyal to a brand. By generating loyalty for search engines, companies expect competitive advantage by having long-term repeat users. Search engine companies attempt to lock their users by adding value added features such as personalized news, email, chat rooms, and permit the users do much more than just search. Though switching to another search engine is only a mouse click away, prior positive usage experience of the search engine, satisfactory search results with a variety of value-added features discourage the users to switch from their popular search engine.

\subsubsection{Brand Popularity}

Popularity measures people's perceptions of how widely something or someone is well-known, well-liked or used (Rose et al., 2004). Brand popularity shows a positive relationship with brand loyalty (Raj, 1985). Accordingly, a popular brand is helpful for attracting more users and developing brand loyalty. Jansen (2005) studied web user searching habits and found that about $14 \%$ of people used popularity as a reason for selecting their primary search engine. One common example would be Google, as "Google" has now become a popular trademark, and it means "Internet search" to many people. So it is not surprising that most of the people choose Google as their primary search engine.

\subsection{User-Related Influences}

Usually the Internet users are not sophisticated searchers showing less mastery over the online searching techniques. Awareness of helpful options and searching techniques are to be translated into good use.

\subsubsection{Emotion towards the Search Engine}

Human factors such as users' experience, cognitive skills or perceptions related to search performances contribute to the online search behavior (Kao et al., 2008; Liaw \& Huang, 2006). The emotions experienced 
during the search activity, consciously or unconsciously can determine the online search performance, decision making process and choice between alternatives (Browne et al., 2007; Bechara \& Damasio, 2005). Flavian-Blanco et al., (2011) studied the emotional outcomes of the online search behavior for using the search engines. They claimed that user used emotion to evaluate the relevance of the search engine results. Positive emotions like happiness and pride would lead to a more favorable attitude towards a search engine, and negative emotions could cause a negative attitude.

Besides the perceived success or failure of a search process, the related emotional outcomes such as stress, anxiety, or frustration feelings have implications on the users' actions on the Web and have been connected to online searching and performance (Charlton, 2009). For instance, perceived success in the search process, initial affective state, perceived effort exerted in the on-line search as well as user emotions experienced during the search process all have an influence on emotion outcome towards search engines (Haubln-Blanco et al., 2011). As the information search process consists of the whole experience of the users, feelings as well as thoughts and actions (Kuhlthau, 1991), every option that the user considers or chooses in searching process can trigger specific emotions that interact with the cognitive system of the user (Bechara \& Damasio, 2005). Therefore, a successful search result along with a feeling of well-paid effort would have a strong positive influence on user attitude towards a search engine.

\subsubsection{User Experience of Search Engines}

Designing a good user experience is important not only for play and leisure related systems but also for search engines because search engines are also that type of systems (Katz, 2010). So designing positive experiences with search engines is so important for the user to use and reuse the system. User experience is the users' overall satisfaction and experience with a product/ system such as a search engine (Katz, 2010) and it is considered to be an act where users engage in search applications using various search tools. When the past experience with a search engine is negative, users tend to avoid the use of that search engine. The user's positive experience could be enhanced by designing a search engine with improved functionalities, by fulfilling or exceeding the user's needs.

\subsubsection{User Experience of Web/Computer}

User experience measures how many years of experience the user has been using the Internet and computer. User experiences include three subgroups: experience with Information Retrieval systems (e.g. Online Public Access Catalogs), experience with computer software (e.g. MS Office), and experience with Internet search tools (Su, 2003b). Liaw \& Huang (2003) suggested that user experience of the Internet and computer experience had a strong influence on user perception of using the search engine. An experienced search engine user will have a stronger knowledge of using the search engine than a new user. Thus, the user with lots of Internet and computer experience will be more likely to use advanced search engine features than the new user and be satisfied with the search engine.

\subsubsection{User's Attitude towards Search Engine}

In psychology, the individual attitude is defined as the reality that an individual has affective or evaluative judgment towards an object or idea or event (Zanna \& Rempel, 1988). In general, attitude is defined as a learned predisposition to respond in a consistently favorable or unfavorable manner toward the object or idea in general (MacKenzie \& Lutz, 1989). In a search engine context, user attitude should be used to refer to a psychological state reflecting the affective or evaluative feelings concerning the search engine (adapted from Hartwick \& Barki, 1994) and may predispose users to respond positively or negatively toward the search engine. Users gather information about search engines, comprehend and link it to their existing knowledge, where after users evaluate the collected information as well as form attitudes and intentions to use search engines. The user attitude towards a search engine can be measured by locating the user's position on a bipolar affective or evaluative dimension such as good/ bad (that is, how good or bad the search engine is perceived to be) (Fishbein \& Ajzen, 1975).

\subsubsection{Faith (Trust) of a Search Engine}

The trust on a search engine lays a significant role in determining search engine use behavior (Rieger, 2009). For example, Pan et al.'s, (2007) laboratory experiments reveal that users' searching is due to their substantial trust in Google's ability to rank results by their true relevance to the user's query. So trust is the confidence in a search engine's ability to retrieve and rank results by their true relevance to a query. Based on the faith over a search engine, the users expect what they are looking for will appear within the first couple of pages and in case if the users cannot find what they seek then they revise the searching by adding additional key words. Users develop a trusting relationship with their favorite search engine, learn about the brand of choice and that usage experience 
leads to repetitive use. Ability of the search engine to satisfy the user and low learning costs incurred by the users in using the search engines are the reasons for repetitive use of the search engine.

\subsubsection{Learning Cost of Current Search Engine}

There is substantial exploratory learning involved in using search engine interfaces (Carroll, 1987) and as a result users develop mental-models out of their various learning activities and apply them to increase (search) task efficiency (Staggers \& Norcio, 1993) and thereby subsequent (search engine) system utilization (Davis \& Bostrom 1993). Firstly, the learning occurs on general pattern of using the search function and this generic learning is transferred to any other engine; secondly the learning occurs on the specific value-added features such as news and email (John \& Kieras, 1996). Most of the search engines are free and available for everyone at anytime. Even so, from the user perspective, it is not totally "free" while a user switches to use another search engine. The learning cost has a significant influence on brand loyalty and consumer selection of the search engine (Telang et al., 2001). Telanget al. (2001) suggested there are two types of learning: learning generic search terms and learning specific search features. It is easy to transfer knowledge for generic search terms because most of the search engines have similar layout and function. However, it could be hard to transfer knowledge on advanced search features because those operations could be very different from one another. For example, the user interface of Google Shopping and Bing Shopping are totally distinct. There is a learning cost associated when a consumer wants to transfer from one shopping search to another.

\subsubsection{Current Browser}

As the search engine is the gate to the Internet, the browser is the gate to the search engine. Different browsers have different default search engines. For example, Bing is the default search engine for Internet Explorer, and Google is the default search engine for Chrome, Firefox, Opera and Safari. The Internet Explorer user will be more likely to use Bing as default search engine other than Google because of the default search engine setting. For example, a user with little or no experience of using the Internet and search enginesis likely to use the default search engine provided by the browser, and switch cost may stop the user from transfer to use another search engine.

\subsection{Effectiveness Related Criteria}

\subsubsection{Relevance of the Results}

Relevance is one of the most important criteria for evaluating search engine's overall effectiveness. Sarah \& Frances (2007) interviewed the university students regarding their opinion towards the search engine evaluation. Nine out of ten participants mentioned relevance is important for user evaluation of the search engine. The retrieved links are to be relevant to the search criteria specified by the user as the main purpose of a search engine is to retrieve relevant results (documents) for a given request (Katz, 2010). From the user's perspective, a thousand irrelevant search results are less useful than one single relevant result because the user only cares about the things he or she is looking for. Many irrelevant results will annoy users, causes information overflow and decrease user satisfaction. The relevance of the results (content relevance) is defined as the degree of correspondence between a retrieved item and the user's information need (Su, 2003a); it is the adequacy and usefulness of the content of a document in response to the user's request (Bing \& Harvold, 1977). In other words, the search results are to be informative with a list of links to web pages with a short summary of the pages; the search results need to avoid fruitless pages and the search results should be sufficiently specific to answer the user's problem.

\subsubsection{Trustworthy Results}

Trustworthy results are important for the search engine user. Consider a user is searching for healthcare information, or buying medical equipment but the search engine returns fake sites on the top. It will result in the user loosing money and further loosing trust in the search engine. Jones \& Timm (2008) studied the comparison of health search engines and found out the search results from the trust worthy source will have a positive impact on consumer evaluation of the search engine.

\subsubsection{Up-to-Date Results}

Having up-to-date information is important for information sources like newspapers, televisions, social networks and search engine. Social media and self-media are changing the way the information is distributed. For example, Soahib Athar, a normal Twitter user was the first person that live-tweeted the death of Osama bin Laden (Anand, 2011). If the search engine company lags behind other information sources, it will lose consumers to its competitors or substitutes. 


\subsubsection{Privacy of Web searches}

Privacy of user information in searching is another major influence in search engine evaluation. The majority of the users are aware that search engines generate advertising revenues based on user's search engine use patterns. At the same time, the users question if their personal search pattern information is being used by the search engine's commercial partners (Rieger, 2009). Privacy can be defined as an individual's ability to determine to what extent personal information should be communicated to others (Westin, 2003). People's attitude towards search engine privacy is based on trust and being informed. According to Sarah \& Frances's study (2007), the majority of the search engine users are aware that the search engine company is using the user's search history in order to generate advertising revenues, and they still trust search engines as an unbiased source of information. However, a lot of people do not know they can access to their search log and manage their privacy setting. Furthermore, data leak or information hacked of search engine can easily destroy user's trust of using its service.

\subsubsection{Ability to Refine the Results}

The quality of search results can be measured as relevance and ability to refine (Sarah \& Frances, 2007). Many search engine users will not get desired results the first time so the ability to refine the search becomes important to help users to narrow down the search results. Search engine features like operators, Boolean and filters are useful for helping the user refine the search and improve effectiveness.

\subsection{Efficiency Related Criteria}

In general the efficiency criteria are given by search time and search strategy (Su, 2003a; 2003b). The search time is the time taken from login to completion of searching on an engine and search strategy refers to the number of search queries submitted by a user in searching for the problem in hand. The other measures are given below.

\subsubsection{Usability/ Ease of Use/ User Interface}

Search engine usability assess how effectiveness and efficiency for the user to use its interface. Many studies suggested usability plays an important role in terms of user evaluation of the search engine (Rieger, 2009; Katz, 2010). High usability will encourage a user to spend more time on the system, develop consumer loyalty and increase satisfaction. Furthermore, high usability could attract more users by lower learning cost and switching cost. We can measure usability from many perceptive, including user interface, navigation and overall ease of use (Vaughan, 1999).

The International Organization for Standardization (2010) defines usability as "The extent to which a product can be used by specified users to achieve specified goals with effectiveness, efficiency, and satisfaction in a specified context of use." Usability is a quality attribute that assesses how easy a user interface for a search engine is to use, and defined by learnability, efficiency, memorability, errors, and satisfaction (Nielsen, 1993). Perceived usability is the degree to which a user believes that using a system (such as search engine) would be free of mental and physical effort (Davis, 1993).

While the emphasis on functionalities of a search engine stresses the importance of the search engine's usability and usefulness, the 'look and feel' and the aesthetic features affect the emotional needs of designers and users (Tractinsky et al., 2000). Issues of visual appeal have become an integral part of interactive system design (Lavie $\&$ Tractinsky, 2004). The users need interactions with search engines to be complete and satisfying for achieving task-oriented goals (like efficiency and effectiveness).

The users look for a powerful and usable interface in an Internet search engine. If the search is difficult to configure, the users are not likely to return to that tool. The readability of the results from the searches also benefit the users a lot (Ziff-Davies, 1995). Using the interface, the users should easily understand search query syntax, should be easy to follow the instructions, clear and well organized.

Usefulness of a search engine is the issue of whether the system can be used to achieve the desired goal of the search-user (Katz, 2010). Perceived usefulness is the degree to which a user believes that using a particular system would enhance his or her job performance (Davis, 1989). It is the comparison of what the search engine is capable of doing with what the user needs to be done by the search job/ task.

\subsubsection{Tools and Features}

Web search engines have never stopped introducing new search tools and features. For example, Google launched Google Map in 2005, Gmail in 2004, Instant Search in 2010, Rich Snippets in 2009 (Blake, 2010). Search engine tools are useful for users to obtain, filter and process information. Therefore, those tools will improve user satisfaction and encourage a user to reuse them. Furthermore, search engine tools and features will 
have an impact on the search engine brand through brand extension (Jansenet al., 2009). A heavy Yahoo! Mail user will be more likely to choose Yahoo! as primary search engine because the email developed by the user shows loyalty to this brand.

\subsubsection{Response Time}

Search engine response time is defined as the time span between the moment the user submits the query and the moment the result page is fully displayed on the screen (Wan, 2000). Response time is critical for websites. Studies showed a user will lose patience if the response time is higher than three seconds, and the user will leave the site if the response time is greater than ten seconds (Stallings, 2008). There are many factors that will influence search engine response time, including user network condition, search engine server condition, technology and displayed content. So even currently most of the major search engines already have really short system response time, but it will still affect user satisfaction and choice.

\subsubsection{User Control during a Search}

The search strategies that the users use to browse information are bookmarking the favorites (for possible revisits), index (using search engines such as Lycos), meta-index (large indices such as Yahoo!), opportunistic (following links from one site to another), and directly typing in the known URLs. Flavian-Blancoet al., (2011) found that the user's perceived control is a critical success factor of the websites. The things that interrupt user's navigation like broken links and pop-up ads will decrease user satisfaction. Shneiderman (1997) claimed that the user who has control during the search will be more often and more rapidly apt to find the results that he or she is looking for, thus the user satisfaction is increased in the end.

\subsubsection{Exposure to Banner Ads}

Exposure to banner ads can cause both attitudinal and behavioral changes (Briggs \& Hollis, 1997). So when the banner ad about the search engine is visited immediately preceding a search engine, can have an impact on choice of the search engine.

\subsection{User Satisfaction}

User satisfaction over a search engine is defined as user's judgment of overall success of a search engine in providing help for specific information need or problem (Su, 2003b). The quality of a search engine is determined by the user satisfaction with the searching methodology of search engines, with the quality of information generated from search engines, and with the functions of search engine (Liaw \& Huang, 2003). The various user satisfaction measures are satisfaction with response time (time taken from submitting a search query till the display of results), satisfaction with search interface (simple or advanced search options and search commands offered by search engine), satisfaction with online documentation (search help, instructions, search tips, FAQs etc), satisfaction with output display (format and components of search output), satisfaction with interaction (information exchange between the user and the search engine), satisfaction with precision (proportion of relevant hits), and satisfaction with time saving (time spent by using an engine to find information) (Su, 2003b).

\subsection{Intend to Use a Search Engine}

Users conduct searches with different goals and understanding their intentions would improve the understanding of user behaviors and thereby improve the design of the search engines (Jansen et al., 2008). The different purposes are (i) navigational searches (queries) that intend to find a specific website such as locating a home page (ii) information searches (queries) that focus on finding information about a specific topic (articles, books, images, maps etc.) and (iii) transactional searches that aim to download (say software) or online shopping (Rose \& Levinson, 2005). So no longer users are intended to use a search engine for simply reading the results or printing information but instead they use for reviewing the results, selecting, linking, downloading, installing, annotating, interpreting, and saving the results (Rieger, 2009). Applying the Technology Acceptance Model (TAM) developed by Davis (1989), the behavioral intention to use a search engine is jointly determined by the perceived usefulness (PU) of the search engine and attitude toward using it; besides, the attitude towards using search engine is determined by PU and perceived ease of use (PEU). PU of search engine is the user's subjective perception of the extent to which the user expects a search engine will aid job performance and PEU is the extent in which the searcher expects a search engine to be easy to learn and use. In general the intend to use a search engine depends on the ranking of the results retrieved by the search engine, the relative position of the results on the screen, the number of results retrieved, online user's search patterns and levels of confidence on their choices (Oulasvirta et al., 2009; Jansen et al., 2008). The intention to use search engines is determined by worthiness to use search engines to find information, usability of search engine to find information, and necessity to use search 
engines to find information (Liaw \& Huang, 2003).

\subsection{Search Engine Usage}

In general the information retrieval systems are designed to provide useful information in response to user's queries (Liaw \& Huang, 2003). The purpose of user interaction with the search engine is not only for finding information but also utilizing the discovered information successfully to accomplish a certain task (Rieger, 2009). As the usage depends on the quality of information system (DeLone \& McLean, 1992) and since a search engine is within the framework of IS, perceived ease of use, enjoyment, and usefulness are functions of search engine (IS) quality. Applying the Technology Acceptance Model (TAM), the search engine users will use a search engine if they believe it will result in positive outcomes: Perceived ease of use (PEU) and perceived usefulness (PU) are the determinants of usage (Davis, 1989). The PEU of a search engine is determined by user-friendliness of search tools, easy to use, easy to connect, and easy to learn how to use search engines to find online information; The PU of a search engine is determined by ability of a search engine to find information quickly, efficiency of search tools, and usability of search engines to find useful information (Liaw \& Huang, 2003).

However, it has been found that the search engine users are unwilling to invest additional effort to improve the searching strategies and often settling on simple key word searches viewing only the first results page by not going beyond 20 results (Haglund \& Olsson, 2008; Jansen et al., 2008) which implies that the search engine users tend to use the most convenient search method and ending the search once the minimally acceptable results are discovered (Rieger, 2009). Besides, the search methodology is often based on "trial and error" without following any specific searching strategy. The perceived usage refers to the amount of time spent interacting with a search engine and the frequency of use, variety of use refers to the importance of use (Igbaria et al., 1995).

\section{Issues for Research}

The conceptual model given in this paper needs to be empirically tested by collecting user-based data for evaluating search engines. Accordingly, the model has to be refined by keeping the valid links in the model. The data for evaluation has to be collected for different search engines in order to generalize the findings. The empirically tested model would identify the key factors that influence user evaluation of search engines and eventually identify the attributes that determine a good search engine, why users repeatedly visit their favorite search engines, and why users switch between different search engines.

The user-related influences such as emotion, user experience of search engines, user's attitude towards search engine, user's faith (trust), learning cost, and current browser on the evaluation of search engine needs more attention. The gap in the literature is to be filled by examining the online search behavior with the use of search engines from user-related influences point of view. Specifically, it could be proposed as user-related influences resulting from a search activity will depend on the perception of search engine success including satisfaction, usage and reuse. Besides, taking into account the user-related influences of the search process, the different profile of the online searchers and their search behavior patterns with different search engines could be explored. In order to analyze the determinants of search engine success, each one of the user-related influences resulting from the search experience could be considered as independent variables and the measures of search engine success including satisfaction and usage could be considered as dependent variables. Given that search for information is part of everyday activity of web users, there is a need for better understanding of the user-related influences. The research has to be carried out to examine and analyze the user-related influences before, during, and after the online search process. Moreover, collecting data about users' search will not be sufficient to measure user-related influences. The research survey to understand the user-related influences should collect information about user's brand awareness, brand loyalty, popular search engines, usability (which varies for each user), user's emotion towards a search engine, user's experience, user's attitude towards a search engine, trust and current browser.

Given the similarity in technology and interface design, the reasons for only a few search engines dominating the web traffic are to be explored. The conceptual model gives both the effectiveness and efficiency criteria for evaluating search engines. For the popularity of a small number of search engines, the predominant criteria affecting the evaluation of search engines are to be explored empirically. The data for this exploration have to be collected based on the search engine user's web searching habits, and which search engine the user used and why. The user-defined criteria for evaluating the popularity of the search engine are to be identified.

\section{Implications and Conclusions}

The implications of this research for searchers, and search engine providers are given in this section. The primary reason for evaluating a search engine is to improve its features and to build a better search engine. In the 
user perspective it is essential to understand whether a search engine is being used effectively and efficiently in a specific search application. This understanding helps the designer for continuously monitoring and tuning the performance of a search engine. The conceptual model given in this paper evolves the effectiveness measures for a search engine's ability to find the right information and efficiency measures for how quickly this finding is done. An ideal search engine should comply with both criteria since as an extremely fast engine is of no use unless it finds the relevant information. The search engines showing poor effectiveness and poor efficiency requires considerable amount of improvement in its design. The user can evaluate different search engines by comparing their performance based on the effectiveness and efficiency criteria $(\mathrm{Su}, 2003 \mathrm{a})$.

Besides effectiveness and efficiency, the other significant consideration in the model is user related influences as search is an interactive process done by different types of users with different information problems. Su (2003b) describes user evaluation of search engine performance based on the following criteria: relevance (degree of usefulness), efficiency (search time and search strategy), utility (value of search results), user satisfaction (response time, search interface, online documentation, output display, interaction, and precision), connectivity (percentage of valid links) and user-related measures. Accordingly the conceptual model includes user satisfaction and usage as the search engine performance variables (the dependent variables). The model could be applied to find the relative performance of various search engines in terms of the above criteria. In addition the model is useful to find the relative performance according to the different user characteristics such as age, gender, experience (use of information retrieval systems, computer and Internet), attitude, emotion, trust and others. One may expect that users with different characteristics may apply different evaluation criteria. It must be mentioned that not all criteria given in the conceptual model are equally important to all users. For instance users with more experience in using computer, Internet and information retrieval systems may give different degrees of importance for various evaluating criteria compare to the less experienced users. Accordingly a search engine may perform poorly for an experienced user but well for less experienced user. The choice of a search engine may also vary according to the difference in user characteristics.

Besides, the model could be applied to compare the search engine's relevance ranking of retrieved items correspond to the user satisfaction of overall success of an engine in providing help for the user's information need or problem. The application of the conceptual model with user defined criteria and the outcomes of evaluation may suggest the areas for improvement for a search engine in terms of improving its effectiveness or efficiency or its branded image. The outcome of the application of the model helps to uncover issues that may or may not be known to the search engine designers or providers.

The conceptual model explains how a typical search engine user would evaluate search engine performance. Regardless of which search engine the searcher uses, the criteria applied for evaluating the search engine remain the same. However, the user-related influences given in the model suggest there might be differences in how the searchers evaluate the search engine performance.As the search engine market place is very dominant, the search engines have to provide more customized and value added services to the users in order to retain them for use and reuse. The effectiveness and efficiency criteria given in the conceptual model should be taken as guidelines and these criteria are to be identified in the search engine context. The content providers of the search engine needs to understand the rationale behind a search engine created web traffic. Once the user leaves the site, the satisfaction or dissatisfaction in using the search engine take over. The relevance of the results with utility plays a crucial role in revisiting the search engine. Therefore, once the searcher is at the search engine site, the content providers should convert the visit into providing value.

\section{References}

Ailawadi, K., Lehmann, D., \& Neslin, S. (2003). Revenue premium as an outcome measure of brand equity. Journal of Marketing, 67, 1-17. http://dx.doi.org/10.1509/jmkg.67.4.1.18688

Ajzen, I. (1991). The theory of plannedbehavior. Organizational Behavior and Human Decision Processes, 50 , 179-211. http://dx.doi.org/10.1016/0749-5978(91)90020-T

Alexa Internet Inc. (March 10, 2008). Top sites United States. Retrieved from $\mathrm{http}: / / \mathrm{www} . a l e x a . c o m /$ site/ds/top_sites?cc=US\&ts_mode=country\&lang=none

Alexa. (2010). Top 500 global sites. Retrieved from http://www.alexa.com/topsites/

Anand, S. (2011). From Abbottabad, Live-Tweeting the Bin Laden Attack. Retrieved from http://blogs.wsj.com/indiarealtime/tag/shoaib-athar/

Baujard, O., Baujard, S., Aurel, C., \& Boyer, R. D. (1998). Appel, Trends in medical information retrieval on internet. Computer Biol. Med., 589-601. http://dx.doi.org/10.1016/S0010-4825(98)00036-5 
Bechara, A., \& Damasio, A. R. (2005). The somatic marker hypothesis: A neuraltheory of economic decision. Games and Economic Behavior, 52(2), 336-372. http://dx.doi.org/10.1016/j.geb.2004.06.010

Bettman, J. R. (1979). An information processing theory of consumer choice. Reading, MA: Addison-Wesley.

Bin, L., \& Lun, K. C. (2001). The retrieval effectiveness of medical information on the web. Int. J. Med. Inform., 62, 155-163. http://dx.doi.org/10.1016/S1386-5056(01)00159-9

Bing, J., \& Harvold, T. (1977). Legal Decision and Information Systems. Oslo: Publications of the Norwegian Research Center for Computers and Law.

Blake, H. (2010). Google celebrates 12th birthday: a timeline. Retrieved from http://www.telegraph.co.uk/technology/google/8027168/Google-celebrates-12th-birthday-a-timeline.html

Briggs, R., \& Hollis, N. (1997). Is There Response Before Click-through. Journal of Advertising Research, 37(2), $33-45$.

Browne, G. J., Pitts, M. G., \& Wetherbe, J. C. (2007). Cognitive stopping rules forterminating information search in online tasks. MIS Quarterly, 31(1), 89-104.

Callery, A., \& Tracy-Proulx, D. (1997). Yahoo! Cataloguing the Web. Journal of Internet Cataloging, 1(1), 57-64. http://dx.doi.org/10.1300/J141v01n01_06

Carroll, J. M. (1987). Interfacing Thought: Cognitive Aspects of Human-computer Interaction. Cambridge, MA: MIT Press.

Charlton, J. P. (2009). The determinants and expression of computer-related anger. Computers in Human Behavior, 25(6), 1213-1221. http://dx.doi.org/10.1016/j.chb.2009.07.001

Courtois, M. P., et al. (1995). Cool tools for searching the web. ONLINE, 19(6), 15-32.

Davis, S. A., \& Bostrom, R. P. (1993). Training End Users: An Experimental Investigation of the Roles of the Computer Interface and Training Methods. MIS Quarterly, 17(1), 61-85. http://dx.doi.org/10.2307/249510

Davis, F. D. (1989). Perceived usefulness, perceived ease of use, and user acceptance ofinformation technology. MIS Quarterly, 13(3), 319-339. http://dx.doi.org/10.2307/249008

Davis, F. D. (1993). User acceptance of information technology: system characteristics, userperceptions and behavioral impacts. International Journal of Man Machine Studies, 38(3), 475-87. http://dx.doi.org/10.1006/imms.1993.1022

Davis, F. D., Bagozzi, R. P., \& Warshaw, P. R. (1989). User acceptance of computer technology: acomparison of two theoretical models. Management Science, 35, 982-1003. http://dx.doi.org/10.1287/mnsc.35.8.982

DeLone, W., \& McLean, E. (1992). Information systems success: the quest for the dependent variable. Information Systems Research, 3(1), 60-95. http://dx.doi.org/10.1287/isre.3.1.60

Fishbein, M., \& Ajzen, I. (1975). Belief, Attitude, Intention and Behavior: An Introduction to Theory and Research. Addison Wesley: Boston, MA.

Flavian-Blanco, C., Gurrea-Sarasa, R., \& Orus-Sanclemente, C. (January 01, 2011). Current Research Topics in Cognitive Load Theory: Analyzing the emotional outcomes of the online search behavior with search engines. Computers in Human Behavior, 27(1), 540-551. http://dx.doi.org/10.1016/j.chb.2010.10.002

Gordon, M., \& Pathak, P. (1999). Finding information on the World Wide Web: the retrieval effectiveness of search engines. Information Processing \& Management, 35, 141-180. http://dx.doi.org/10.1016/S0306-4573(98)00041-7

Haglund, L., \& Olsson, P. (2008). The impact on university libraries of changes in informationbehaviour among academic researchers: A multiple case study. Journal of AcademicLibrarianship, 34(1), 52-59. http://dx.doi.org/10.1016/j.acalib.2007.11.010

Hartwick, J., \& Barki, H. (1994). Measuring user participation, user involvement, and user attitude. MIS Quarterly, 18(1), 59-82. http://dx.doi.org/10.2307/249610

Häubl, G., \& Trifts, V. (2000). Consumer decision making in online shopping environments: the effect of interactive decision aids. Marketing Science, 19(1), 4-21. http://dx.doi.org/10.1287/mksc.19.1.4.15178

Igbaria, M. T., Guimares, T., \& Davis, G. B. (1995). Testing the determinates of microcomputer usagevia a structural equation model. Journal of Management Information Systems, 4, 87-114.

International Organization for Standardization. (2010). ISO 9241-210:2010. Retrieved from 
http://www.iso.org/iso/iso_catalogue/catalogue_tc/catalogue_detail.htm?csnumber $=52075$

Jansen, B. J., Booth, D. L., \& Spink, A. (2008). Determining the informational, navigational, andtransactional intent of Web queries. Information Processing \& Management, 44(3), 1251-1266. http://dx.doi.org/10.1016/j.ipm.2007.07.015

Jansen, B. J., Zhang, M., \& Schultz, C. D. (2009). Brand and its effect on user perception ofsearch engine performance. Journal of American Society for Information Science and Technology, 60(8), 1572-1595. http://dx.doi.org/10.1002/asi.21081

Jenkins, C., Jackson, M., Burden, P., \& Wallis, J. (1998). Searching the World Wide Web: an evaluationof available tools and methodologies. Information and Software Technology, 39, 985-994. http://dx.doi.org/10.1016/S0950-5849(97)00061-X

Jeuland, A. P. (1979). Brand Choice Inertia as One Aspect of the Notion of Brand Loyalty. Management Science, 25(7), 671-82. http://dx.doi.org/10.1287/mnsc.25.7.671

John, B., \& Kieras, D. E. (1996). The GOMS family of user interface analysis techniques: Comparison and Contrast. ACM Transactions on Human Computer Interactions, 3(4), 320-351. http://dx.doi.org/10.1145/235833.236054

Johnson, F. C., \& Crudge, S. E. (2007). Using the repertory grid and laddering technique to determine the user's evaluative model of search engines. Journal of Documentation, 60(2), 259-280.

Johnson, F. C., Griffiths, J. R., \& Hartley, R. J. (2001). DEVISE: A Framework for the Evaluation ofInternet Search Engines. Library and Information Commission Research Report 100, 63(2), 278.

Jones, D., \& Timm, D. (2008). Consumer Health Search Engines Comparison. Journal of Hospital Librarianship, 8(4), 418-432. http://dx.doi.org/10.1080/15323260802391936

Kao, G. Y. M., Lei, P. L., \& Sun, C. T. (2008). Thinking style impacts on Web searchstrategies. Computers in Human Behavior, 24(4), 1330-1341. http://dx.doi.org/10.1016/j.chb.2007.07.009

Katz, A. (2010). Aesthetics, Usefulness and Performance of user-search - Engine Interaction. Journal of Applied Quantitative Methods, 5(3), 424-445.

Keller, K. L. (2007). Strategic brand management: Building, measuring, and managing brand equity (3rd ed.). Upper Saddle River: Prentice Hall.

Keller, K. L. (January 01, 1993). Conceptualizing, Measuring, and Managing Customer-Based Brand Equity. The Journal of Marketing, 57(1), 1-22. http://dx.doi.org/10.2307/1252054

Kim, J. (2009). Describing and predicting information-seeking behavior on the Web, Journal ofthe American Society for Information Science and Technology, 60(4), 679-693.

Kotler, P. (1967). Marketing management: analysis, planning, and control. Englewood Cliffs, N.J: Prentice-Hall.

Kraut, R., Scherlis, W., Mukhopadhyay, T., Manning, J., \& Kiesler, S. (1996). The HomeNet Field Trial of Residential Internet Services. Communication of the ACM, 39(12), 55-63. http://dx.doi.org/10.1145/240483.240493

Kuhlthau, C. C. (1991). Inside the search process: Information seeking from theuser's perspective. Journal of the American Society for Information Science, 42(5), 361-371. http://dx.doi.org/10.1002/(SICI)1097-4571(199106)42:5<361::AID-ASI6>3.0.CO;2-\#

Lavie, T., \& Tractinsky, N. (2004). Assessing dimensions of perceived visual aesthetics of websites. Human-Computer Studies, 60(2), 269-298. http://dx.doi.org/10.1016/j.ijhcs.2003.09.002

Leroy, G., Xu, J., Chung, W., Eggers, S., \& Chen, H. (2007). An end user evaluation of query formulation and results review tools in three medical meta-search engines. International Journal of Medical Informatics, 76, 780-789. http://dx.doi.org/10.1016/j.ijmedinf.2006.08.001

Liaw, S. S., \& Huang H. M. (2003). An Investigation of user attitudes toward search engines as an information retrieval tool'. Computers in Human Behavior, 19(2003), 751-765. http://dx.doi.org/10.1016/S0747-5632(03)00009-8

Liaw, S. S., \& Huang, H. M. (2006). Information retrieval from the world wide web: Auser-focused approach based on individual experience with search engines.Computers in Human Behavior, 22(3), 501-517. http://dx.doi.org/10.1016/j.chb.2004.10.007 
Lopes, C. T., \& Ribeiro, C. (2011). Comparative evaluation of websearch engines in healthinformation retrieval. Online Information Review, 35(60), 869-892. http://dx.doi.org/10.1108/14684521111193175

MacKenzie, S. B., \& Richard, J. L. (1989). An Empirical Examination of the Structural Antecedents of Attitude Toward the Ad in an Advertising Pretest Context. Journal of Marketing, 53(April), 48-65. http://dx.doi.org/10.2307/1251413

Mostafa, J. (2005). Seeking better Web searches. Scientific American, 292(2), 67-73. http://dx.doi.org/10.1038/scientificamerican0205-66

Nielsen, J. (1993). Usability Engineering, AP Professional.

OCLC. (2005). Perceptions of libraries and information resources. Dublin, Ohio: OCLC. Retrieved from http://www.oclc.org/reports/2005perceptions.htm

Oulasvirta, A. N., Hukkinen, J. P., \& Schwartz, B. (2009). When more is less: Theparadox of choice in search engine use. In Proceedings of the 32nd internationalACM SIGIR conference on research and development in information retrieval (pp.516-523). Boston, MA.

Pan, B., Hembrooke, H., Joachims, T., Lorigo, L., Gay, G., \& Granka, L. (2007). In Google we trust: Users' decisions on rank, position, and relevance. Journal of Computer-Mediated Communication, 12(3). http://dx.doi.org/10.1111/j.1083-6101.2007.00351.x

Pew Internet \& American Life Project. (2006). Online Health Search 2006. Retrieved from http://www.pewinternet.org/PPF/r/190/report_display.asp

Raj, S. P. (January 01, 1985). Striking a Balance between Brand "Popularity" and Brand Loyalty. The Journal of Marketing, 49(1), 53-59. http://dx.doi.org/10.2307/1251175

Rangaswamy, A., Giles, C. L., \& Seres, S. (2009). A strategic perspective on searchengines: Thought candies for practitioners and researchers. Journal of Interactive Marketing, 23, 49-60. http://dx.doi.org/10.1016/j.intmar.2008.10.006

Rieger. (2009). Search Engine use behavior of Students and Faculty: User perceptions and Implications for future research. First Monday, 14(12). Retrieved from http://www.uic.edu/htbin/cgiwrap/bin/ojs/index.php/fm/art

Rose, A. J., Swenson, L. P., \& Waller, E. M. (January 01, 2004). Overt and relational aggression and perceived popularity: developmental differences in concurrent and prospective relations. Developmental Psychology, 40(3), 378-87. http://dx.doi.org/10.1037/0012-1649.40.3.378

Rose, D. E., \& Levinson, D. (2005). Understanding user goals in Web search. Proceedings of the 13th International Conference on World Wide Web (Chiba, Japan), pp. 391-400.

Rowley, J. (1998). The Electronic Library (4th ed.). Facet Publishing, London, pp. 181, 186-7.

Sarah, E. C., \& Frances, C. J. (January 01, 2007). Using the repertory grid and laddering technique to determine the user's evaluative model of search engines. Journal of Documentation, 63(2), 259-280. http://dx.doi.org/10.1108/00220410710737213

Shneiderman, B. (1997). Direct manipulation for comprehensible, predictable and controllable user interfaces. IUI '97 Proceedings of the 2nd international conference on Intelligent user interfaces. http://dx.doi.org/10.1145/238218.238281

Spink, A. (2002). A user-centered approach to evaluating human interaction with Web searchengines: An exploratory study. Information Processing and Management, 38(3), 401-426. http://dx.doi.org/10.1016/S0306-4573(01)00036-X

Spink, A., Wolfram, D., Jansen, B. J., \& Saracevic, T. (2001). Searching the web: the public and their queries. Journal of the American Society for Information Science and Technology, 52(3), 226-34. http://dx.doi.org/10.1002/1097-4571(2000)9999:9999<::AID-ASI1591>3.0.CO;2-R

Staggers, N., \& Norcio, A. F. (1993). Mental Models: Concepts for Human-Computer Interaction Research. International Journal of Machine Studies, 38, 587-605. http://dx.doi.org/10.1006/imms.1993.1028

Stallings, W. (2008). Business Data Communications. Prentice Hall, Computer networks.

Stern, B. B. (2006). What does brand mean? Historical-analysis method and construct definition. Journal of the Academy of Marketing Science, 34(2), 216-223. http://dx.doi.org/10.1177/0092070305284991 
$\mathrm{Su}$, L. (2003a). A comprehensive and systematic model of user evaluation of web search engines: I. Theory and background. Journal of the American Society for Information Science and Technology, 54(13), 1175-92. http://dx.doi.org/10.1002/asi.10303

$\mathrm{Su}, \mathrm{L}$. (2003b). A comprehensive and systematic model of user evaluation of web search engines: II. An evaluation by undergraduates. Journal of the American Society for Information Science and Technology, 54(13), 1193-223. http://dx.doi.org/10.1002/asi.10334

Sutcliffe, A. M. E. (1998). Towards a cognitive theory of information retrieval. Interact. Computing, 10(1998), 321-351. http://dx.doi.org/10.1016/S0953-5438(98)00013-7

Telang, R., Mukhopadhyay, T., \& Wilcox, T. R. (2001). An Empirical Analysis of Internet Search Engine Choice. Retrieved from http://www.econ2.jhu.edu/people/harrington/375/tmw01.pdf

Tractinsky, N., Katz, A. S., \& Ikar, D. (2000). What is beautiful is usable. Interacting with Computers, 13(2), 127-145. http://dx.doi.org/10.1016/S0953-5438(00)00031-X

Vaughan, J. (1999). Considerations in the choice of an Internet search tool. Library Hi Tech., 17(1), 89-110. http://dx.doi.org/10.1108/07378839910267262

Venditto, G. (1996). Search engine showdown. Internet World, 7(4), 79-86.

Wan, H. A. (October 01, 2000). Opportunities to enhance a commercial website. Information \& Management, 38(1), 15-21. http://dx.doi.org/10.1016/S0378-7206(00)00048-3

Westin, A. F. (July 01, 2003). Social and Political Dimensions of Privacy. Journal of Social Issues, 59(2), 431-453. http://dx.doi.org/10.1111/1540-4560.00072

Ye, G., \& Van, R. W. F. (January 01, 2004). Brand equity: extending brand awareness and liking with Signal Detection Theory. Journal of Marketing Communications, 10(2), 95-114. http://dx.doi.org/10.1080/13527260410001693794

Yi, Y., \& Jeon, H. (January 01,2003 ). Effects of loyalty programs on value perception, program loyalty, and brand loyalty. Journal of the Academy of Marketing Science, 31(3), 229-240. http://dx.doi.org/10.1177/0092070303031003002

Zanna, M. P., \& Rempel, J. R. (1988). Attitudes: a new look at an old concept. In Bar-Tal D., \& Kruglanski A. (Eds.), The social psychology of knowledge (pp. 315-334). New York: Cambridge University Press.

Ziff-Davis Publishing Company (1995). Hide and go seek: rating internet search engines. Retrieved from $\mathrm{http}: / / \mathrm{www} . z d n e t . c o m / p c c o m p /$ features/internet/search/sub1.html 